It must, however, be admitted that there are still many puzzling features of the primary current. In allochromatic crystals the photoelectric response and the absorption of light correspond very well, but in idiochromatic crystals the photoelectric response has a maximum near the long wave edge of the absorption band and falls off very rapidly in the interior of the band where the absorption is large. It therefore seems that, when the absorption is large, there is no conductivity (the absorption of the light which produces the photo-effect in allochromatic crystals is always small). This seems to mean that, when many electrons are excited in say diamond, they go into discrete states and not into a band. One can see vaguely that, when many atoms have electrons excited, the original classification of states into bands, based on the properties of a perfect lattice, is likely to break down, and to be replaced by a classification based on the properties of the individual atoms, but such an explanation cannot be considered as satisfactory. This and many other problems must await further developments of the theory before they can be tackled successfully.

${ }^{1}$ A. H. Wilson, Proc. Roy. Soc., A, 138, 458; 1931 : and 134, 277 ; 1931.

2Reviews of Modern Physics, 4, 723; 1932.

\title{
Hormones and Evolutior
}

\section{By J. T. Cunningham}

ACCORDING to the most advanced results $A$ of genetical research, evolution is to be investigated by statistical and mathematical methods. The researches and conclusions of the geneticists are governed by the conceptions of species and divergence. It is obvious that the production of the many varieties of rabbits, dogs, and other mammals, and of birds, under domestication, to say nothing of plants, is an example of evolution; and it may possibly be to a great degree, if not entirely, explained by random mutation and survival. But the geneticists ignore many other phenomena which are equally or more important than the origin of varieties or species, especially the phenomena of adaptation. They regard survival as equivalent to selection, but that term as used by them means usually indirect selection. The survival is attributed to greater viability or fecundity, not to the utility of diagnostic characters. Genetics include extraordinary discoveries concerning sexlinkage, but almost nothing about sex-limited characters, which are known to be inherited by both sexes but developed exclusively or to a greater degree in one.

The doctrine of genes appears to be satisfactory in relation to variation and the origin of varieties and species, but it fails to explain adaptive evolution. When we consider the origin of terrestrial from aquatic vertebrates, the various adaptations of limbs to flight in birds, mammals, and some extinct reptiles, the reversed adaptation of air-breathing vertebrates to aquatic life, and many other obvious and direct adaptations, it is a truism to say that their development in the individual depends on genes in the nuclei of ova and sperms, but it has not yet been shown that they can be explained by any random mutation of the genes. The difficulty is still greater when we consider metamorphosis. It may be admitted that the metamorphosis of the flat-fish is the result of its genetic constitution, although we do not know precisely how the genes produce the hereditary characters in development. But here we have a change in important structural characters from a symmetrical phase with the median plane vertical to an asymmetrical phase with the median plane horizontal, a change taking place gradually in post-embryonic life and corresponding with the change in the relation of the fish to the direction of light and gravity.

We are asked to believe that this co-relation of structural development with external forces is not due to any effect produced by those forces, but to random mutations in the genes which were independent of the external forces, and the survival of those mutations which had the complex co-relation which we see. If we used the mathematical symbols of which the modern geneticist is so fond, how should we express the probability of the production of such an adaptation by random mutation and selection? The gene theory in this case must assume that every conceivable mutation may occur, including those which determine the change from symmetry to asymmetry in the individual, and that sooner or later each is bound to occur, so that selection is omnipotent. But there is no evidence of the occurrence under experiment or observation of the occurrence, uninfluenced by external conditions, of anything like the distortion of the skull which causes the change in the position of the eyes in the flat.fish, and leaves the symmetry of the anterior and posterior regions of the skull unaffected.

The problem of evolution can be attacked from either end of the ontogeny, from the genes to the development of the characters, or from the characters back through development to the genes. Adaptation does not consist merely in the possession of characters which are supposed to be useful or beautiful like the spots on the back of a beetle or the ocelli in a peacock's tail, but also of the functions of organs and their relation to the organism's

No. 3294, VoL. 130] 
mode of life. One of the most curious phenomena to be explained is the influence of internal secretions or hormones on development and function. In the case of the antlers of stags the exclusive development in the male is due to the hormone secreted by the testes. This is an example of the sex-limitation of organs only indirectly related to the reproductive function. In the female mammal the functional cycles of the accessory reproductive organs which form such a remarkable difference in them from the birds and reptiles, are also controlled by hormones. In 1908 I put forward the theory that the origin of the influence of the testicular hormone on characters limited to the male could be explained by the inheritance of the effects of external stimulation. In the case of the stag, the development of the antlers according to this theory was due to the mechanical stimulation of the periosteum of the frontal bone by blows and friction in the fighting between rival stags, and both this development and its association with the presence of the testicular hormone were transmitted to the reproductive cells or gametes, in modern terminology to the genes. No theory of random mutation originating in the genes affords any reason for the evolution of this peculiar association of the sex-limited character with the internal secretion of the testis.

With regard to the female mammal, I suggested that the origin of the reproductive cycle and its hormonic control could be traced to the retention of the ovum in the oviduct during its development, and the stimulation of the uterine walls by the nutrition and growth of the embryo and by the placenta. Similarly the mammary glands on this theory were primarily due to the mechanical stimulation of the skin by the sucking of the young which led to the hypertrophy of dermal glands. Afterwards it was discovered that the anterior lobe of the pituitary produces one or more hormones which influence oestrus and the formation of corpora lutea in the ovary. Cases of precocious sexual maturity in the human subject have been found associated with tumours of the adrenal body. In order to cover such facts, I extended my theory to all the endocrine organs, postulating that the hypertrophies caused by the developing foetus were inherited not merely in association with the hormone of the ovary or ovarian follicles, but also in association with the normal hormone complex, so that excess or defect in any one of the more active of these organs caused abnormalities in the sexual cycle: injection of pituitrin, for example, causing formation of corpora lutea, the modification in mammals of the ovarian follicles from which ova have been discharged.

Apparently the secretion of the pituitary is the most active of the hormones not derived from the reproductive system itself, and it has the most marked influence on the ovary in the mammal. But it has no such effect on frogs or oviparous reptiles or birds, although it produces the same secretion in these animals. If the formation of corpora lutea were the effect of gestation, this result at the beginning of the evolution of gestation would occur in association with the presence of pituitrin in the body. If the acquired character were transmitted to the genes it would still be in association with pituitrin, so that injection of the latter would cause the formation of corpora lutea when there was no ovum or fotus in the uterus. The action of a hormone on this theory suggests an analogy with that of the associated stimulus in a 'conditioned reflex'.

The physiologist finds that the secretion of the pituitary affects the phases of the reproductive cycle, and concludes that the gland goes through a cycle which oauses the reproductive cycle. But that is no explanation; the question still remains what causes the pituitary to pass through such a cycle in mammals and other viviparous vertebrates and not in oviparous forms. On the theory that the external stimulation, that is, the presence of the developing ova in the ovi. duct, was the original cause and that the effects of this were inherited in association with the hormone plexus, we have an explanation, whereas genetics and physiology give none. This extension to the whole hormone complex of my theory of the association of secondary sexual characters and the female sexual cycle in mammals with the hormones of the reproductive organs was communicated to the Second International Congress for Sex Research, held in London in 1930.

Having given so much attention to the subject, I was very much interested in the letter by Prof. Landsborough Thomson on the evolution of hormones published in NATURE of October 8. This is the first discussion by any other biologist than myself, which has come to my notice, of the evolution of the relation between hormones and development, especially with reference to sexlimited characters and accessory reproductive organs. Prof. Thomson naturally uses technical physiological terms which are unfamiliar to other biologists, such as 'integrative mechanism' for the action of one part on another by which the functions of the organs are co-ordinated. He refers to the evidence that some of the chemical linkages have been established by the evolution of a tissue responsive to a substance already present in the organism. He thus agrees with me on the point that the hormones were in existence before the responsive tissues or developments were evolved.

It is therefore not the evolution of the hormones which has to be explained, but the evolution of the response to the hormones. I hope that Prof. Thomson will consider the theoretical suggestions which I have published and agree that external stimulation (regarding the ovum and developing embryo in the oviduct or uterus as really external to the organism) affords a reason for the evolution of the special responses, while the doctrine of random mutation cannot be applied to this case because the obvious association of the new development, whether corpus

No. 3294, VoL. 130] 
luteum, mammary gland, or antlers in the stag, with a new stimulation is inconsistent with the term random.

Prof. Thomson refers to the vestigial survival in the mammal of the substance which causes expansion of chromatophores in Amphibia and teleosts. But is not the fact rather that the pituitary remains the same while the chromatophores have disappeared in the mammal? He also refers to the discovery that the development of the crop gland in the pigeon is stimulated by a (or, the) hormone of the pituitary which also stimulates the development of the mammary glands of the guinea pig. Here is an instance in which it is evident that the conception often implied in such terms as 'the œstrusproducing hormone' is not strictly correct, that the hormone does not cause the special development of tissue but that its presence is necessary to the development of which the potentiality is present in the genetic constitution. The testis hormone is necessary to the normal development of the antler in the stag but does not produce antlers in the stallion. Usually in experimental biology the pituitary of the ox is employed for researches on vertebrates of various classes, fishes, amphibia, birds and mammals, which implies the assumption that the internal secretions of the organ are essentially similar in all these classes. My theory that the mechanical stimulation, in one case of the membrane of the bird's crop, in the other of the dermal glands of the mammal, caused hyper- trophy which in course of time affected the genes within the reproductive cells in association with the hormones of the pituitary, so that the hypertrophies became hereditary, is in harmony with the facts to be explained.

The case is quite similar to that of male sexlimited characters in mammals, where the testis hormone influences the development of antlers in stags, of teeth in the boar, and of the snout in certain seals. There are different responses to the same hormone, but the different responses correspond with different external stimulations. If it be replied that there is no evidence that the effect of such stimulations on the soma can produce any change in the genes, I can only point out that the association of the external stimulation with the presence of the hormones corresponds with the associations of the hormones with genetic development, and that it is impossible to ignore the fact that the hereditary hypertrophy controlled by hormones is physiologically of the same nature as the effects of the external stimulation, and the other fact that the stimulation is not merely hypothetical and supposed to have occurred at some remote period in the past but continues at the present day.

\section{REFERENCES}

Cunningham, J. T. Archiv für Entwickelungsmechanik, Bd. 26, 1908; "Hormones and Heredity." London, Constable and Co., 1921; "The Evolution of Secondary Sexual Characters and of Accessory Reproductive Organs." Proc. Second Internat. Congress for Sex Research, 1930.

\section{Obituary}

\section{Canon John Roscon}

$\mathrm{W}^{\mathrm{t}}$ HEN in the 'nineties of last century I had the great good fortune to make the acquaintance of my valued friend, the late Canon John Roscoe, he was settled as a missionary of the Church Missionary Society among the Baganda, the great tribe or nation which has given its name to Uganda, in Central Africa. But he had previously resided in the same capacity for some years in that part of East Africa now called Tanganyika, which was afterwards taken over by Germany and known as German East Africa. Of his life in that country and his observations of the native tribes he has given a brief account in a volume published long afterwards, "Twenty-five Years in East Africa". The account includes the notice of a curious form of human sacrifice practised by the natives which he succeeded in suppressing. $\mathrm{He}$ left the country at the time when the Germans took possession of it, and falling into the hands of the Arabs, who opposed the German invasion, he and his wife narrowly escaped being put to death by their captors, the messenger who brought their ransom only arriving about an hour before the time fixed for their execution.

It was not until he settled among the Baganda, however, that Roscoe began systematically to investigate and record the customs and beliefs of the natives among whom he lived. The results of his observations were first published in a series of valuable articles in the Journal of the Anthropological Institute, which are perhaps not wholly superseded by his systematic work on the subject, "The Baganda", which appeared some years later, in 1911. In his researches among the Baganda, he received important aid from his friend, the native prime minister of Uganda, who was not only himself versed in the lore of his people but also brought as informants from all parts of the country old men acquainted from their youth with the ancient traditions and customs which even then, at the beginning of the twentieth century, had passed or were passing out of use and even out of memory. Thus by his timely intervention, and the efficient help of his native informants, Roscoe was able to put on record a large body of information on the old life of the Baganda which otherwise would inevitably have been lost to science. His writings on the Baganda must therefore remain for all time the standard authority on that important tribe, one of the most powerful and most politically developed of all the Bantu peoples.

While his researches were in the main concen.

No. 3294, Vol. 130] 